\title{
ANALYSIS OF THE COMBUSTION PROCESS OF LOW-CALORIFIC GASEOUS FUELS IN EXPERIMENTAL COMBUSTION CHAMBER OF GAS TURBINE
}

\author{
P. Grzymislawski*, J. Jojka**, M. Golebiewski ${ }^{* * *}$, P. Czyzewski ${ }^{\dagger}$
}

\begin{abstract}
This paper presents the combustion process of gaseous fuels in turbine combustion chamber. Authors investigated fuels with significant amount of inert gases like nitrogen and carbon dioxide. For selected fuels, experimental studies in an experimental silo combustion chamber were performed. During the experiment the effect of molar fraction of nitrogen and excess air ratio on the temperature and gas composition inside and in the outlet channel of the combustion chamber were analyzed. At the same time the numerical calculation were performed with using Cantera and Ansys FLUENT software. Basic parameters like adiabatic flame temperature and laminar flame speed and process of the flow with combustion in simplified geometrical model of combustion chamber were calculated. Results from CFD calculation were compared qualitatively with the experimental result. The CFD part was supplemented with a calculation with carbon dioxide used as inert gas. Research on utilization of fuels like biogases, nitrogen-rich natural gases and their mixtures is very important, especially in countries where energy production is based on coal and lignite. The use of these kind of fuels in high-performance combined cycle allow to significantly reduce emission of toxic compound into the atmosphere.
\end{abstract}

Keywords: gas turbine, NO emission, numerical simulation, combustion, alternative gaseous fuels

\section{Introduction}

Nowadays the energy production plays an important role in life of citizens. The demand for the energy, heat and electricity, is still growing and force us to look for new solutions and new energy sources, including renewable and alternative fuels. The most of energy consumed in industry and domestic sectors are coming from combustion processes of fossil fuels. The negative aspect of this process is emission of toxic compound such as nitric oxides (NO) carbon monoxide (CO) and unburned high hydrocarbons (THC). The domestic emission was described by (Urbaniak et al. 2015), emission from gas turbine (Correa 1993; Lefebvre \& Ballal 2010) while the emission from gas engines was presented in the work provided by (Ślefarski et al., 2018). The emission limits according to EU legislation require introduction of new low emission and high efficiency combustion systems such as Flameless Combustion or Zonal Volumetric Combustion presented by (Szewczyk et al., 2015). To fulfil new more restrictive emission limits the classical construction process should be supported by numerical calculation based on fluids mechanic codes like Ansys Fluent, OpenFoam (Tyliszczak et al., 2016). In case of combustion process the codes include chemical reaction like Chemkin or Cantera (Jójka \& Ślefarski 2017) are applied.

\footnotetext{
* Przemyslaw Grzymislawski, PhD Eng.: Chair of Thermal Engineering, Faculty of Machines and Transport, Poznan University of Technology, Street Piotrowo 3; 60-965 Poznan; PL, przemyslaw.grzymislawski@put.poznan.pl

** Joanna Jojka, PhD student.: Chair of Thermal Engineering, Faculty of Machines and Transport, Poznan University of Technology, Street Piotrowo 3; 60-965 Poznan; PL, joanna.w.jojka@put.poznan.pl

*** Michal Golebiewski, PhD student: Chair of Thermal Engineering, Faculty of Machines and Transport, Poznan University of Technology, Street Piotrowo 3; 60-965 Poznan; PL, michal.e.golebiewski@doctorate.put.poznan.pl

$\dagger \quad$ Pawel Czyzewski, PhD student: Chair of Thermal Engineering, Faculty of Machines and Transport, Poznan University of Technology, Street Piotrowo 3; 60-965 Poznan; PL, pawel.a.czyzewski@doctorate.put.poznan.pl
} 
In the paper the results of numerical calculation of non-standard gaseous fuels combustion process in silo gas turbine combustion chamber using Ansys Fluent CFD software are presented. Two operational parameters of gas turbine, temperature distribution and NO emission were presented and compared with experimental data.

\section{Experimental and numerical setup}

Experimental tests were performed in testing gas turbine combustion chamber. The test rig was adapted to laboratory conditions, by reduction of dimensions which resulted in a change of power and air flow. Main parameters affecting the combustion process like air distribution, inlet velocities, swirl number, were the same like in original combustion chamber. The combustion chamber is presented in Fig. 1:a).

a)

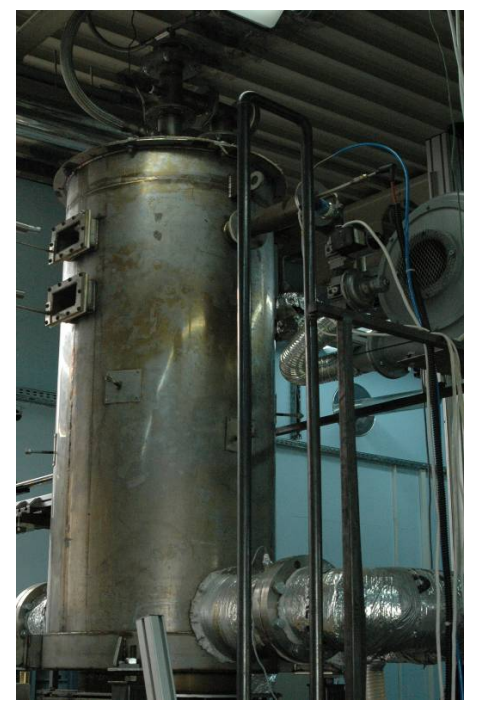

b)

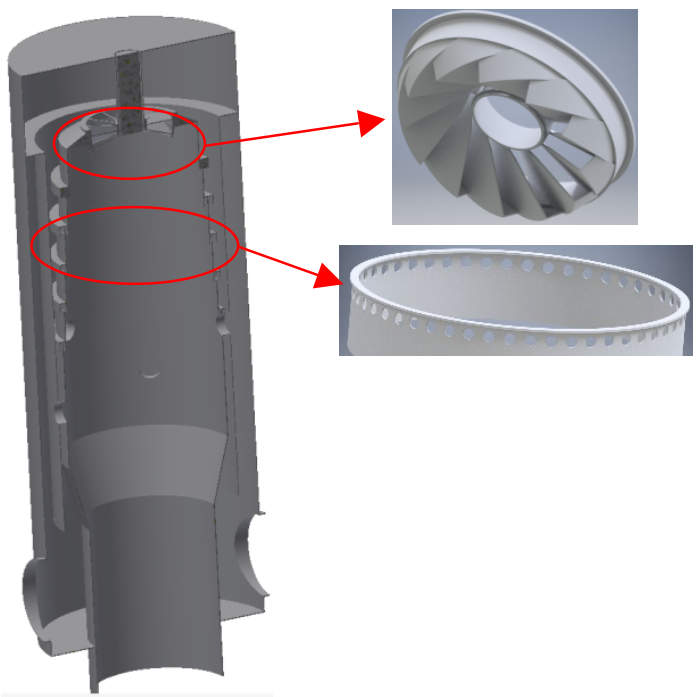

Fig. 1: a) Picture of the combustion chamber, b) 3D model of the combustion chamber with zoom on swirler and cooling holes.

During the experiment the temperature, chemical compounds $\left(\mathrm{CO}, \mathrm{CO}_{2}, \mathrm{O}_{2}, \mathrm{NO}\right)$ content inside the combustion chamber and flue gas composition were measured. For that purpose, the Suction Pyrometer probe with S-thermocouple and Emerson gas analyzers were used.

Based on 3D model of the combustion chamber (Fig. 1:b) a simplified geometrical model of the combustion chamber for numerical simulation was prepared. Main simplification related to swirler and cooling holes. For each of the three levels of cooling air, the round holes were replaced with corresponding cross-sectional area. All internal walls were modeled as thin surfaces.

In the experiment, only fuels with nitrogen as inert gas were examined, while in the numerical simulation two additional fuels with carbon dioxide as inert gas were investigated. Tested fuels parameters are presented in Tab. 1:.

Tab. 1: Fuel composition, mole fraction.

\begin{tabular}{c|cccccc} 
& Methane & $\begin{array}{c}\text { Methane- } \\
80\end{array}$ & $\begin{array}{c}\text { Methane- } \\
65\end{array}$ & $\begin{array}{c}\text { Methane- } \\
50\end{array}$ & $\mathrm{CO}_{2}-10$ & $\mathrm{CO}_{2}-20$ \\
\hline $\mathrm{CH}_{4}[\%]$ & 100 & 80 & 65 & 50 & 90 & 80 \\
\hline $\mathrm{N}_{2}[\%]$ & - & 20 & 35 & 50 & - & - \\
\hline $\mathrm{CO}_{2}[\%]$ & - & - & - & - & 10 & 20 \\
\hline $\mathrm{LHV}\left[\mathrm{MJ} / \mathrm{Nm}^{3}\right]$ & 35.89 & 28.72 & 23.33 & 18.21 & 32.30 & 28.72 \\
\hline
\end{tabular}

The fuel was prepared in a gas mixer. Methane was taken from the public natural gas network and nitrogen was delivered from the tank. To set exact composition, Bronkhorst mass flow controllers were used. The fuel flow was set to obtain $400 \mathrm{~kW}$ of thermal power. For each tested fuel the global excess air 
ratio $\lambda_{\mathrm{G}}$ were changed in range from 1.85 to 3.00 in five steps. The same values of global excess air ratio $\lambda_{\mathrm{G}}$ were adopted numerical simulations.

Numerical calculations were divided into two stages - calculations of basic parameters describing combustion processes using Cantera software and CFD calculations using Ansys Fluent. In the Cantera, the results of laminar combustion velocity and adiabatic flame temperature were obtained. These calculations were made for different temperatures of substrates and the air excess coefficient in the range of $0.5 \div 3.0$. In the Ansys Fluent calculations, the resulting flow, temperature and chemical compounds fraction inside the combustion chamber were determined.

\section{Results and discussion}

Distribution of chemical compounds and temperature inside the combustion chamber was measured with using of Suction Pyrometer probe. For that purpose, additional measuring holes are needed, which may influence on the results. It can be seen in Fig. 2:, where NO and temperature distribution is presented. The probe was introduced into the chamber from the left side. Close to the wall temperature is low, which is result of air leakage around the probe and effect of cooling of the probe. Then oxygen reacts with fuel in area of air deficiency and the temperature is rising. It causes increase of NO emission according to thermal mechanism.

a)

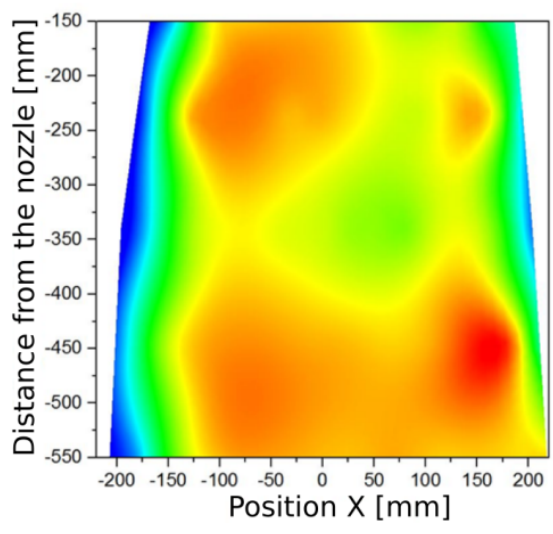

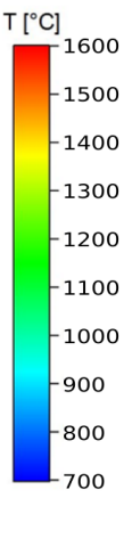

b)

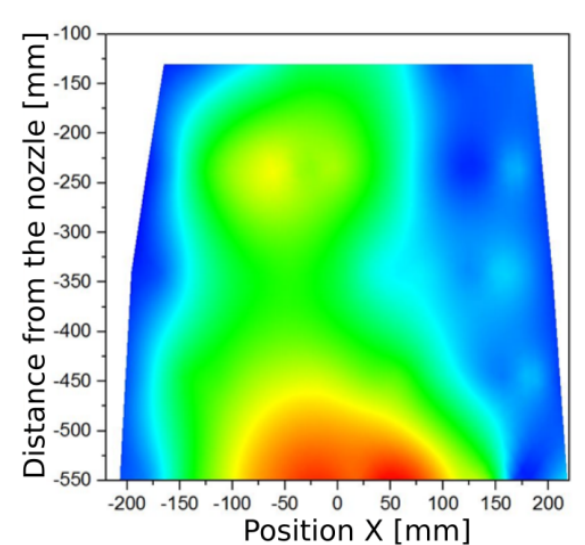

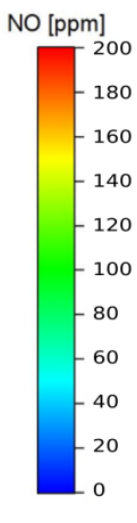

Fig. 2: Distribution of temperature a) and nitric oxide b) for fuel Methane.

CFD calculation allowed to obtain the results of air distribution in the combustion chamber. For every case the distribution is almost the same and average values are presented in Fig. 3:.

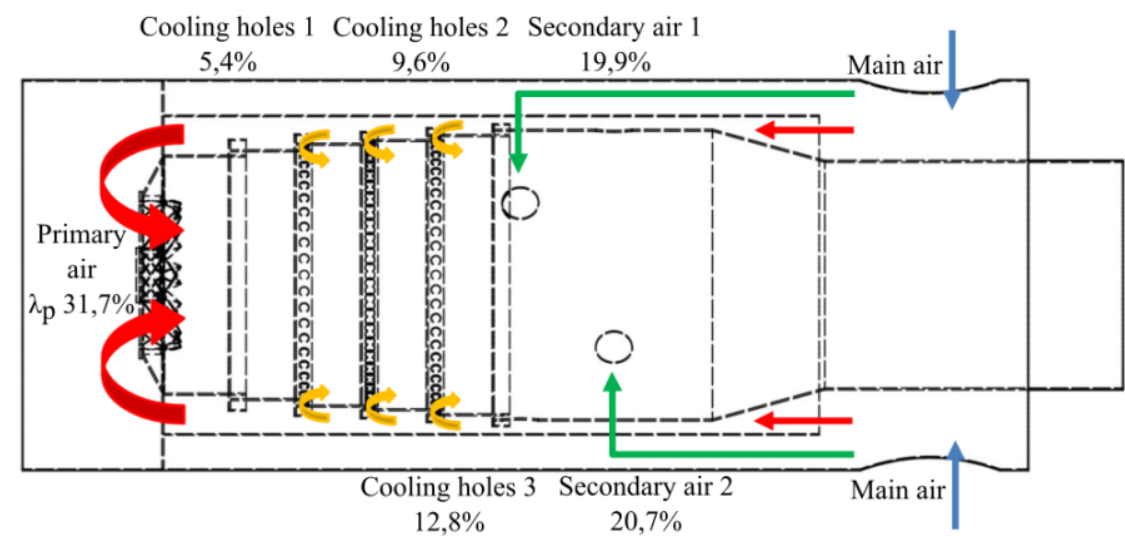

Fig. 3: Average air distribution in the combustion chamber for all cases.

Such air distribution forces maintaining high values of the excess air coefficient. Only for $\lambda_{\mathrm{g}}$ larger than 2.6 , in the region of the burner the amount of air is close to stoichiometric. Thanks to this, the reaction $\mathrm{CH}_{4} \rightarrow \mathrm{CO}_{2}$ is rapid and the amount of $\mathrm{CH}$ radicals responsible for $\mathrm{NO}$ formation according to prompt mechanism (Fenimore, 1971) is low. In addition, the high value of the excess air coefficient lowers the temperature, which reduces the formation of nitrogen oxides in accordance with the Zeldowicz thermal mechanism. 
Numerical investigation allowed to observe the air cooling effect on three levels of cooling holes. The temperature close to the walls was about $400{ }^{\circ} \mathrm{C}$ lower than maximum.

Analysis of the results showed that the composition of the fuel and the excess air coefficient affects the internal recirculation zone and the length of the flame. The greater amount of inert gases increases the area of recirculation zone and shortens the flame. As the air volume increases, the recirculation zone narrows and the flame lengthens.

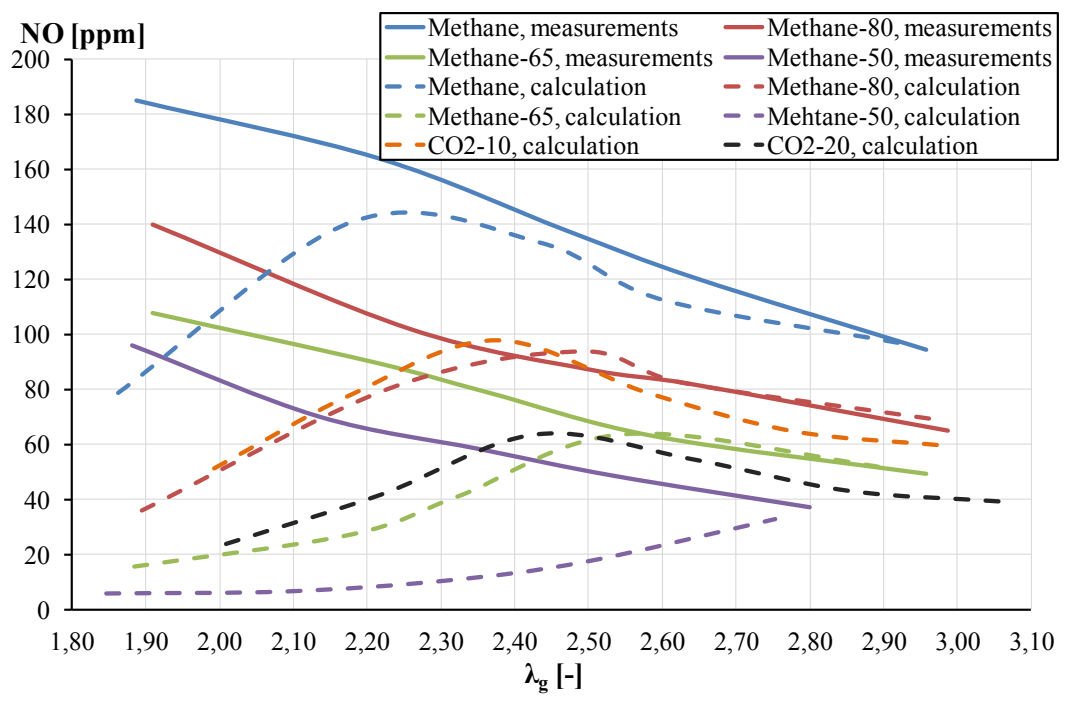

Fig. 4: NO emission in function of global excess of air.

Fig. 4: presents a comparison of results obtained during the experiment and numerical calculations. The results are characterized by a high convergence in the range of high values of the global air excess coefficient. The discrepancy for low values results from the use of postprocessing method during NO calculations, which works properly in the range of stoichiometric combustion (in this case the primary coefficient of air excess is of high importance)

\section{Conclusions}

Based on the results presented, the following conclusions can be drawn:

- Combustion of low calorific gaseous fuels may reduce the emission of NO,

- It is possible to get a stable flame for low calorific gases in a wide range of operating condition,

- It is possible to combust different gases without burner modification.

\section{References}

Correa, S.M., 1993. A Review of NO x Formation Under Gas-Turbine Combustion Conditions. Combustion Science and Technology, 87(1-6), pp. 329-362.

Fenimore, C.P., 1971. Formation of nitric oxide in premixed hydrocarbon flames. Symposium (International) on Combustion, 13(1), pp. 373-380.

Jójka, J. \& Ślefarski, R., 2017. Dimensionally reduced modeling of nitric oxide formation for premixed methane-air flames with ammonia content. Fuel, 217, pp. 98-105.

Lefebvre, A.H. \& Ballal, D.R., 2010. Gas turbine combustion: alternative fuels and emissions Third.

Szewczyk, D. et al., 2015. Experimental study of the combustion process of gaseous fuels containing nitrogen compounds with the use of new, low-emission Zonal Volumetric Combustion technology. Energy, 92, pp. $3-12$.

Ślefarski, R. et al., 2018. Analysis of Combustion Process in Industrial Gas Engine with Prechamber-Based Ignition System. Energies, 11(2), p. 336.

Tyliszczak, A., Boguslawski, A. \& Nowak, D., 2016. Numerical simulations of combustion process in a gas turbine with a single and multi-point fuel injection system. Applied Energy, 174, pp. 153-165.

Urbaniak, R., Bartoszewicz, J. \& Kłosowiak, R., 2015. Main Causes of NOx Emissions by Low-Power Boilers. Polish Journal of Environmental Studies, 24(5), pp. 2223-2230. 